\title{
DESENVOLVIMENTO E MODELAGEM DE TRANSDUTOR FOTOELÉTRICO DESTINADO A MÁQUINAS CORTADEIRAS PARA EMBALAGENS FLEXÍVEIS
}

\author{
Décio Colaneri* \\ decio.colaneri@yahoo.com.br \\ Claudio Garcia ${ }^{\dagger}$ \\ claudio.garcia@poli.usp.br \\ ${ }^{*}$ Rua Joaquim Moraes, 35 - CEP 04370-020 - São Paulo, SP - Brasil \\ ${ }^{\dagger}$ Departamento de Engenharia de Telecomunicações e Controle, Escola Politécnica da Universidade de São Paulo \\ Av. Prof. Luciano Gualberto, trav. 3, nr. 158 - CEP 05508-900 - São Paulo, SP - Brasil
}

\section{RESUMO}

Atualmente há um emprego abundante de embalagens flexíveis nos produtos comercializados no varejo: biscoitos, chocolates, balas etc. A impressão dessas embalagens normalmente é feita em folhas, cuja largura é da ordem de $1 \mathrm{~m} \mathrm{e}$ que, ao longo de sua largura, podem conter diversas embalagens individuais. Essas embalagens são fornecidas à empresa embaladora na forma de bobinas, as quais devem então ser seccionadas longitudinalmente, para separar as tiras que as compõem. Apresentam-se aqui o projeto e o desenvolvimento de um transdutor fotoelétrico, incumbido de auxiliar no corte longitudinal das embalagens flexíveis. Tratase do desenvolvimento de um produto de concepção totalmente inovadora, pela não utilização de componentes clássicos de geometria óptica (lentes, prismas e filtros), caracterizado pela simplicidade construtiva, baixo custo e alto desempenho. Analisam-se e comparam-se diversas tecnologias de sensores ópticos e define-se o sensor fotoelétrico como sendo a melhor opção para esta aplicação, tanto do ponto de vista técnico quanto econômico, sendo então descritas características técnicas desse sensor. É feita ainda a montagem de um transdutor fotoelétrico com o sensor selecionado e a modelagem matemática do mesmo. Os testes realizados mostraram que o transdutor desenvolvido está plenamente apto a operar

\footnotetext{
Artigo submetido em 21/09/2005

1a. Revisão em 10/10/2006

2a. Revisão em 20/08/2007

Aceito sob recomendação do Editor Associado

Prof. Paulo Eigi Miyagi
}

em máquinas cortadeiras-rebobinadeiras de última geração, cuja velocidade pode atingir $800 \mathrm{~m} / \mathrm{min}$.

PALAVRAS-CHAVE: sensor óptico, transdutor fotoelétrico, embalagens flexíveis, máquinas cortadeiras-rebobinadeiras.

\begin{abstract}
Flexible packaging has been widely employed in retail products such as biscuits, chocolates, candies etc. The packaging is normally printed on sheets around $1 \mathrm{~m}$ wide, which can have several packages printed side by side, covering all its width. This packaging is supplied to the packaging company in individual spools and parted longitudinally, to separate the strips that compose them. The project and the development of a photoelectric transducer to help the longitudinal cut of the flexible packaging are here presented. This paper reports the development of a product with a totally innovative concept, which does not use classic components of optical geometry (lenses, prisms and filters), characterized by constructive simplicity, low cost and high performance. Different technologies of optical sensors are analyzed and compared; then, the photoelectric sensor is defined as the best option for this application, not only from the technical point of view, but also from the economical one. Next, the technical characteristics of this sensor are described. Finally, the assembly of a photoelectric transducer with the selected sensor and its mathematical modeling is performed. The tests show that the developed transducer is fully able to operate in slitter-
\end{abstract}


rewinder machines of last generation, whose speed can reach $800 \mathrm{~m} / \mathrm{min}$.

KEYWORDS: optical sensor, photoelectric transducer, flexible packaging, slitter-rewinder machines.

\section{INTRODUÇÃO}

Durante as últimas décadas, os sistemas rotativos de impressão vêm dominando o mercado mundial, particularmente quando grandes volumes e uma produção em larga escala são considerados fatores primordiais. Para tal sucesso, cada vez mais se intensificou a substituição do homem pela máquina, minimizando com isto tolerâncias e obtendo-se melhores resultados. Acompanhando esta tendência, a indústria de embalagens flexíveis conquista também importante destaque, adaptando-se à grande transformação sofrida pelo mercado, não apenas em termos quantitativos, mas também pelas mudanças originadas como reflexo de hábitos de consumo e estilos de vida diversificados. Este amadurecimento exige cada vez mais que novas tecnologias sejam disponibilizadas em resposta a essa demanda evolutiva.

As embalagens flexíveis levam esse nome por serem confeccionadas com materiais básicos maleáveis (que doravante serão generalizados por suporte) como o papel, celofane, filmes plásticos, náilon, finas folhas de alumínio etc, ou com combinações destes, formando as chamadas estruturas complexas. Sua utilização abrange o campo das indústrias alimentícia, farmacêutica, cosméticos, fertilizantes e muitas outras.

Este artigo inicia apresentando a caracterização de um problema onde, durante a fase de acabamento do processo de uma estrutura de embalagem flexível, se faz necessário a exploração óptica de uma linha-guia impressa. A seguir se mostra um histórico de soluções tecnológicas utilizadas, bem como conceitos para detectar linhas impressas. Em seguida se descreve o desenvolvimento e implementação de um dispositivo transdutor fotoelétrico, apresentando as curvas de resposta do mesmo. Por fim, apresenta-se a modelagem matemática dinâmica de um dispositivo transdutor fotoelétrico.

\section{DESCRIÇÃO SUCINTA DA GERAÇÃO DE EMBALAGENS FLEXÍVEIS}

O suporte, matéria-prima principal, é recebido na forma de bobinas e a impressão geralmente é o primeiro beneficiamento ao qual é submetido. Para os trabalhos com alto grau de exigência de qualidade, os equipamentos mais comumente utilizados no processo rotativo de impressão de embalagens são as máquinas impressoras offset, seguidas pelas rotogravuras e flexográficas.

\subsection{Processo Rotativo de Impressão de Embalagens}

Este tipo de impressão - gravuras rotativas - é feita de modo contínuo, onde, em cada estágio da máquina, é impressa uma cor. As impressões, à medida que se sucedem, são superpostas sem desvios, resultando num perfeito encaixe. Tantos serão os estágios percorridos pelo suporte quantas forem as cores que compõem a estampa desejada (Soroda, 1996).

Em um estágio final, o suporte é então rebobinado, porém não com a mesma perfeição da bobina original, pois, após percorrer uma longa trajetória, sofre deslocamentos transversais e muitas outras deformações. Estas deformações são provocadas por várias razões, que vão desde as variações estruturais do suporte até tolerâncias mecânicas da própria máquina impressora. Pode-se concluir que com esses deslocamentos, a impressão das estampas, apesar de estar em perfeito encaixe, sofre constantes variações de posição em relação às bordas do suporte.

Após a etapa de impressão, o suporte, via de regra, passa por beneficiamentos complementares, até que seja formada a estrutura complexa final desejada. Alguns desses processos são, por exemplo, a aplicação de ceras (coating), metalização e os acoplamentos com outros suportes (extrusão e laminação). A cada etapa formadora da estrutura, às quais o suporte original é submetido, novas agressões do tipo aquecimento/ resfriamento, desbobinamento/rebobinamento ocorrem, somando um acúmulo apreciável de imperfeições na bobina resultante.

A bobina que perfaz a embalagem já totalmente beneficiada pode conter, ao longo de sua largura, mais de uma embalagem individual. Neste caso, ela deve ser transformada em bobinas singelas através de seccionamentos longitudinais, que no processo de fabricação são denominados de operação de corte e rebobinamento. As bobinas resultantes devem ter diâmetros e larguras que correspondam às especificações das máquinas embaladoras do cliente final.

\subsection{Máquina Cortadeira-Rebobinadeira}

A Figura 1 ilustra o processo de acabamento em uma máquina cortadeira-rebobinadeira controlada por um sistema servo-posicionador, constituído pelos itens 1,2 e 3 da referida figura.

Ao ser alimentada com bobina impressa e beneficiada (4) bobina mãe - o corte e o rebobinamento são processados simultaneamente. Imediatamente após o corte, as faixas são rebobinadas individualmente (5), formando assim a embalagem que efetivamente irá beneficiar o produto final. A largura das faixas seccionadas (6) é ajustada mecanicamente 


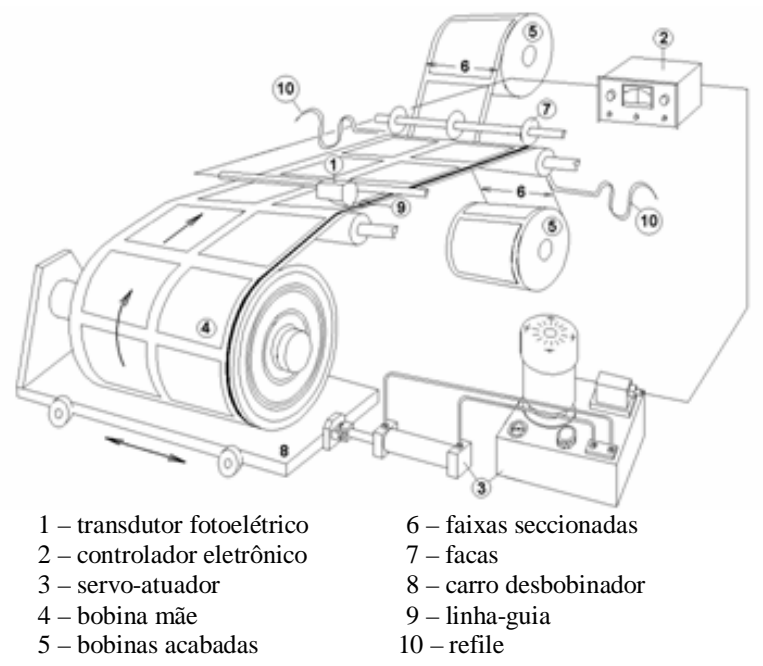

Figura 1: Máquina cortadeira equipada com sistema servoposicionador.

através do posicionamento de um conjunto de facas (7) afixadas em um eixo comum. O alinhamento do suporte para o corte é realizado pelo deslocamento transversal do carro desbobinador (8) que suporta a bobina mãe. Esta ação, neste caso, é realizada por um servo-atuador hidráulico compreendido por uma unidade geradora de pressão, cilindro e servoválvula (3).

À medida que o processo se desenvolve, é necessário que o posicionamento transversal do suporte seja constantemente aferido, para que alcance as facas na posição correta de corte. Esta função cabe ao transdutor fotoelétrico (1), que deve detectar uma linha-guia (9), impressa na lateral do suporte. O sinal elétrico gerado pelo transdutor fotoelétrico é enviado a um controlador eletrônico (2) que, após processamento, gera e transmite um comando de potência para acionamento do dispositivo servo-atuador (3).

Quando bobinados aleatoriamente (caso da bobina mãe, item 4 - Figura 1), os materiais flexíveis sofrem desvios laterais progressivos, cujo sentido se alterna freqüentemente. Este comportamento representa a característica típica de um padrão de desvio em rampa. Um desvio do tipo degrau, neste caso, não é normal e poderia ter como consequiência a ruptura do suporte e, conseqüentemente, a interrupção do processo.

Em média, a tolerância de desvio de corte aceitável é de $\pm 0,2 \mathrm{~mm}$. A prática determina que atuadores com velocidade máxima de correção na faixa entre 25 a $60 \mathrm{~mm} / \mathrm{s}$ satisfazem plenamente aos processos de corte/rebobinamento para velocidades de trabalho de até $800 \mathrm{~m} / \mathrm{min}$ (Erhardt-Leimer, 2005).

\subsection{Padrão da Linha-Guia Impressa}

Além da busca de altas taxas de produtividade e aprimoramento constante da qualidade, uma grande preocupação da indústria moderna tem sido também a minimização dos desperdícios ou quebras de processo. Um item inevitável e intrínseco ao processo de fabricação de embalagens flexíveis impressas corresponde aos refiles (item 10, Figura 1), tiras laterais que são expurgadas durante o procedimento de corte/rebobinamento.

A diminuição gradativa do refile fez com que surgisse um padrão minimizado de linha-guia impressa, de modo que uma das margens da linha ficasse praticamente colada ao desenho da embalagem propriamente dita. Em conseqüência, a detecção da linha impressa necessariamente só pode ser feita mediante a leitura do contraste da borda livre da linha com o suporte. A Figura 2 ilustra um exemplo de linha-guia impressa aplicada em um refile reduzido.

Por questões de objetividade, é considerada neste trabalho a referência de contraste formada por uma linha-guia de cor preta impressa sobre um suporte de papel de cor branca.

\section{REVISÃO DA TECNOLOGIA}

Os detectores de posição de linha impressa com sinal de saída proporcional, destinados à fabricação de embalagens flexíveis, sempre estiveram associados à necessidade de se integrar um sistema servo-posicionador com a finalidade de se efetuar a correção do ponto de corte longitudinal em bobinas,

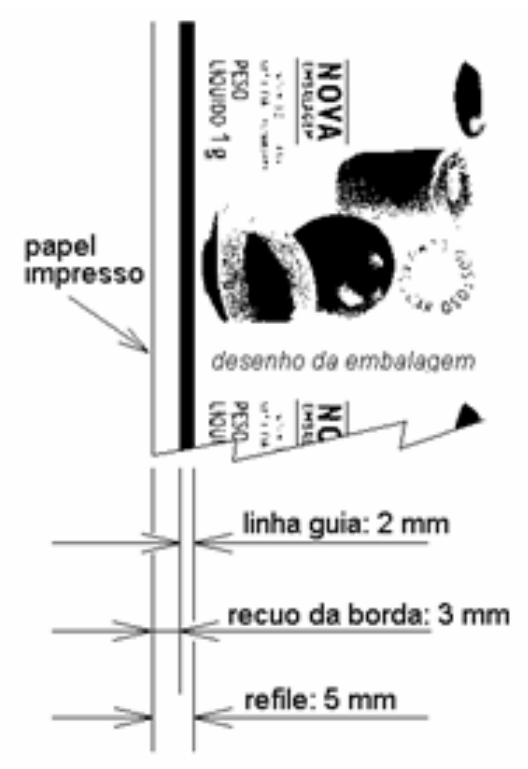

Figura 2: Linha-guia padrão. 
durante o processo de seccionamento. Por este motivo, tais dispositivos, até então, sempre foram integralmente desenvolvidos pelas próprias empresas especializadas no projeto e construção destes sistemas. Por conseqüência, uma bibliografia específica sobre o assunto praticamente inexiste, a não ser pela coletânea de manuais, artigos gerados a partir de exposições e eventos, bem como boletins técnicos contendo históricos. Trata-se de um produto cuja liderança de fabricação ainda se concentra em poucos países, como EUA, Itália e Alemanha.

\subsection{Elementos Fotossensíveis}

Elementos fotossensíveis são aqueles que podem transformar as variações de fluxo luminoso em variações de grandezas elétricas. Os fotossensores mais comumente utilizados podem ser apresentados nos seguintes tipos básicos (Günter; Stiles, 1967): fotoemissão, efeito fotovoltaico, fotocondução por junção, fotocondução de efeito de volume (bulk-effect, fotorresistor, fotocélula ou LDR - light dependent resistor) e fotoelétrico de carga acoplada (CCD - Charge Coupled Device).

\subsubsection{Dispositivos Fotoemissivos}

Os primeiros equipamentos a surgirem para medição de nível de luz, como no caso da detecção de linhas impressas, utilizavam células do tipo fotoemissiva. Um dos modelos precursores desse tipo de equipamento denominava-se "Trakatron", desenvolvido na década de 50 pela empresa inglesa Crosfield Electronics Limited.

A concepção de funcionamento do detector fotoelétrico, chamado de cabeça exploradora (Figura 3a), inspirava-se no princípio de varreduras utilizada pela televisão. Continha uma lâmpada incandescente e um pequeno motor síncrono, cujo eixo era acoplado a um disco rotativo montado com 5 lentes (Figura 3b). Por meio destas, um ponto luminoso projetado no suporte, varria o campo por onde passava a linhaguia impressa.

Cada vez que um destes pontos luminosos passava diante da janela de vidro da cabeça exploradora (6), a mudança de luz provocava um impulso de detecção em uma célula fotoelétrica. Um segundo impulso acontecia quando o ponto luminoso passava diante da linha impressa. O tempo compreendido entre estes dois impulsos de tensão fornecia indiretamente o posicionamento lateral da bobina que estava sendo processada.

Apesar de possuir boa sensibilidade e rápida velocidade de resposta, as células fotoemissivas apresentavam uma fragilidade susceptível às agressividades sempre presentes em ambientes industriais. Outras desvantagens eram sua vida limi-

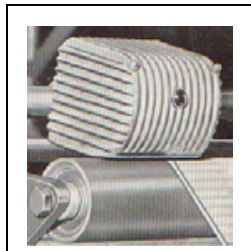

(a)

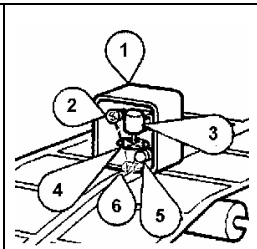

- Cabeça exploradora

2 - Lâmpada

3 - Motor

4 - Disco de lentes

5 - Célula fotoemissiva

6 - Janela de vidro

(b)

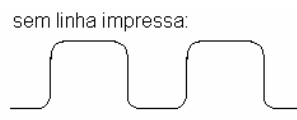

presença de linha impressa: $\rightarrow \quad$ posição da linha

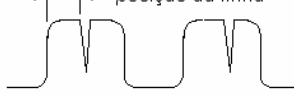

(c) sinais elétricos gerados - freqüência de varredura: $400 \mathrm{~Hz}$

Figura 3: Cabeça exploradora modelo Universal da Crosfield com célula fotoemissiva. (Fonte: Colaneri Engenharia)

tada, a necessidade de fontes de luz de potências elevadas, amplificação eletrônica próxima, devido ao baixo nível de potência captado, alto custo e grande dimensão. Os modelos de células dessa categoria mais utilizados eram o $90 A G$ e o $90 \mathrm{AV}$, ainda remanescentes em equipamentos de antiga geração.

\subsubsection{Dispositivos de Fotocondução por Efeito Bulk - Fotorresistor - LDR}

Com a evolução dos componentes semicondutores e células fotorresistivas, o domínio dos fotoemissíveis praticamente se extinguiu. Na década de 60, a empresa norte-americana Fife (http://www.maxcessintl.com) lançava um modelo de detector óptico utilizando um dispositivo fotorresistor que rapidamente dominou o mercado (Figura 4a). Ao invés do sistema de varredura, a detecção era feita pela medição do contraste apresentado por uma das margens da linha-guia impressa e o suporte.

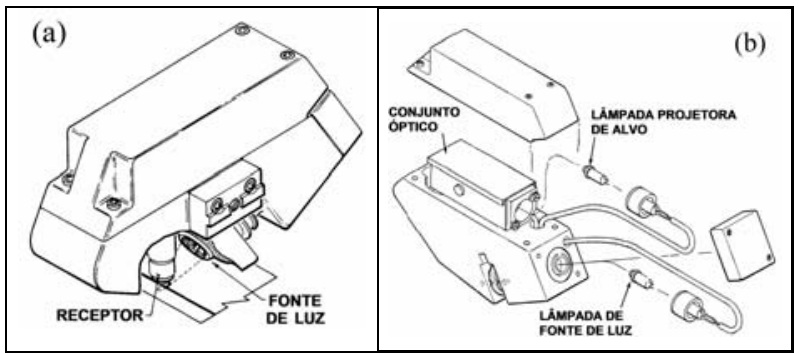

Figura 4: Leitor óptico modelo SE-2201 da Fife com célula fotorresistiva. (Fonte: Colaneri Engenharia) 


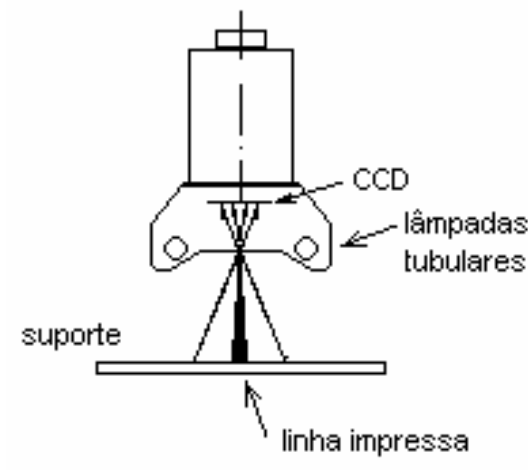

Figura 5: Leitor óptico modelo SO2 da Re utilizando dispositivo fotoelétrico CCD.

Mesmo com esta inovação, o conjunto óptico incorporado ao detector era ainda extremamente complexo e delicado, resultando também num instrumento de grandes dimensões e custo elevado.

\subsubsection{Dispositivos Fotoelétricos de Carga Aco- plada - CCD's}

A empresa italiana $R e$ (http://www.re-spa.com) foi uma das primeiras a lançar um sistema de detecção de linha impressa utilizando sensoriamento por varredura a CCD - Figura 5, ao invés das tradicionais células fotovoltaicas, fotocondutores por junção ou fotorresistores.

Apesar das inúmeras vantagens associadas aos dispositivos CCDs, algumas limitações de operação ainda são experimentadas, principalmente quando aplicados em máquinas rebobinadeiras que trabalhem com uma grande diversidade de materiais.

\section{CONCEITOS PARA A DETECÇÃO DA LINHA IMPRESSA}

O posicionamento transversal da linha-guia (e, conseqüentemente, da impressão como um todo) em relação a um ponto fixo de observação pode ser efetuado medindo-se o nível de luz refletida pelo papel, que contém a linha impressa. A condição ideal para que essa leitura seja feita é com a disposição frontal do elemento sensor em relação à linha impressa, de modo que o sensor receba os raios de luz que correspondam à reflexão difusa normal proveniente do papel, como apresentado na Figura 6 (Hecht, 1974).

À medida que o papel se desloca lateralmente, o nível de luz refletida sofrerá alterações, excursionando de um valor máximo, Figura 7(a), até atingir um valor mínimo, Figura 7(c).

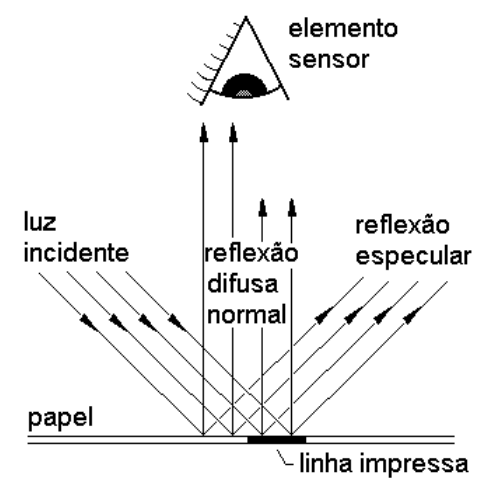

Figura 6: Elemento sensor sensibilizado por reflexão difusa normal de luz.

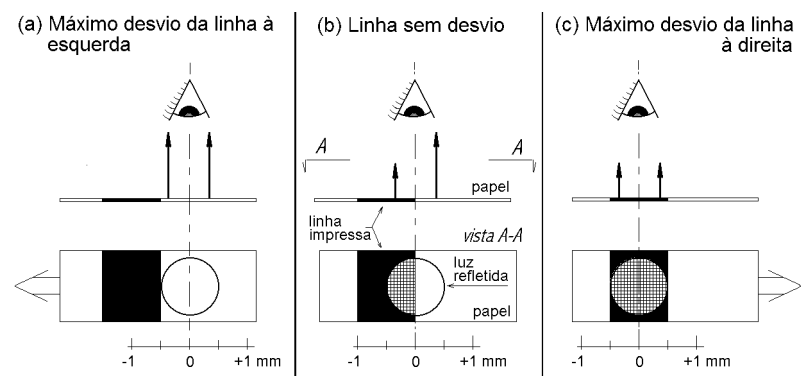

Figura 7: Alterações do nível de luz refletida ao elemento sensor em função da posição da linha-guia impressa.

Se nenhuma outra fonte de luz perturbar o processo, pode-se afirmar que esta é a situação em que o elemento sensor apresenta o maior nível de sensibilidade (ganho), pois responde ao completo deslocamento da linha impressa com a máxima variação de nível de luz refletida.

\subsection{Dispositivo para Ensaios de Desloca- mentos}

Com a finalidade de realizar os ensaios para seleção do elemento sensor, bem como experimentos do transdutor fotoelétrico, foi construído um dispositivo mecânico capaz de executar deslocamentos progressivos com precisão de $0,01 \mathrm{~mm}$. Para realizar os movimentos com os graus de precisão e repetibilidade necessários, foi utilizado um relógio comparador instrumento de metrologia mecânica.

O croqui completo do conjunto medidor de desvios é apresentado na Figura 8.

O relógio comparador (1) foi afixado horizontalmente sobre uma base metálica revestida com borracha (2). Na extremidade da haste móvel do relógio, adaptou-se uma mesa extremamente leve e rígida em perfil de alumínio (3), que acompa- 

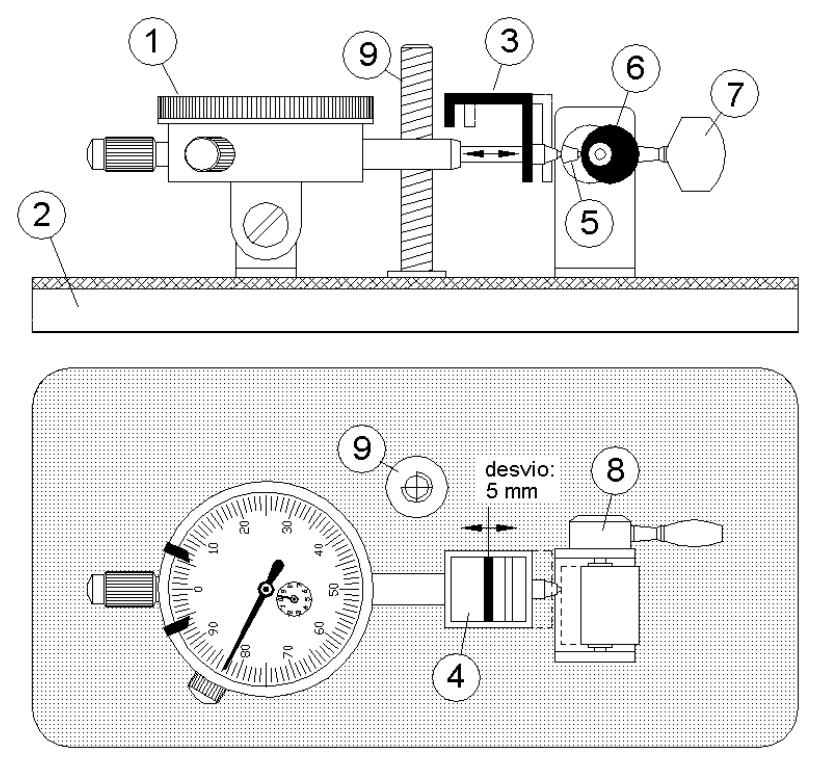

Figura 8: Medidor de desvios de amostras de suportes com linhas-guia impressas. Curso: $5 \mathrm{~mm}$ - precisão: 0,01 mm.

nha fielmente a haste, quando submetida a um deslocamento.

O plano da mesa está dimensionado para receber amostras de papel impresso (4) de até 20 x $20 \mathrm{~mm}$, o suficiente para acomodar a linha-guia padrão especificada. Devido à ação da mola em seu interior, a ponta apalpadora do relógio comparador (5) é constantemente pressionada contra a superfície de um tambor cilíndrico (6). O tambor possui um eixo excêntrico que, quando girado em 180 graus, promove um deslocamento linear de $5 \mathrm{~mm}$ na haste do relógio comparador. Os deslocamentos podem ser efetuados girando-se o botão (7) que está acoplado ao eixo de entrada do mini-redutor mecânico (8), permitindo uma ação precisa e segura.

\subsection{Dispositivo para Ensaios Dinâmicos}

Para a realização de ensaios dinâmicos nos elementos submetidos a teste, foi desenvolvido um dispositivo capaz de gerar sinais de contraste tipos rampa e/ou degrau. Os detalhes construtivos do dispositivo é apresentado na Figura 9.

Um disco (2) com uma máscara (4) aplicada em uma das superfícies é afixado ao eixo de um pequeno motor de corrente contínua (3), cuja velocidade de rotação pode ser variada. Esta máscara, confeccionada em papel branco, apresenta figuras impressas na cor preta de forma que, ao girar, provocará variações de contraste em rampa e/ou degrau, de acordo com o ensaio que se pretenda realizar.

O dispositivo submetido a teste deve ser posicionado frontalmente ao disco, conforme mostrado em (1). A distância

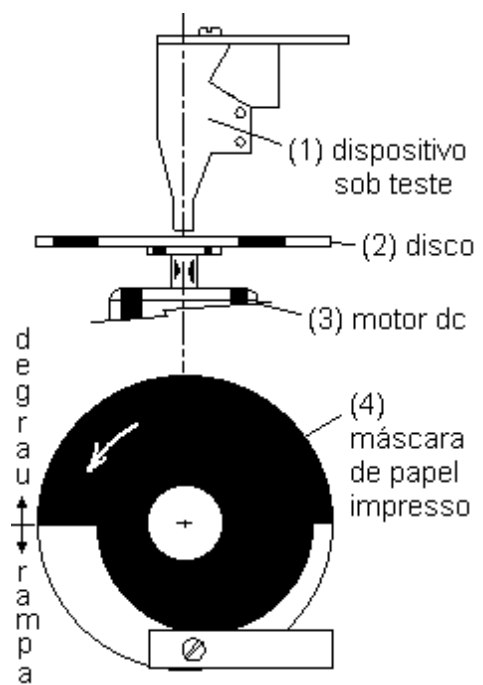

Figura 9: Dispositivo gerador de impulsos em rampa e/ou degrau.

entre a face sensível do dispositivo e o plano do disco deve ser ajustada de acordo com a conveniência do experimento.

\subsection{Seleção do Elemento Sensor}

Analisando-se as características e particularidades das diversas técnicas e tipos de elementos fotossensíveis apresentados, optou-se por utilizar um dispositivo fotorresistivo que apresentasse a capacidade de, simultaneamente, captar uma ampla faixa de contrastes representados pelas cores definidas no espectro da visão humana, adequar-se a uma grande diversidade de suportes impressos, ter baixo custo e boa robustez mecânica.

A seleção de um dispositivo fotorresistivo requer a determinação de dois grupos distintos de parâmetros: a escolha do material fotocondutivo mais apropriado para a aplicação e a determinação da configuração mais adequada. Analisando-se pelo aspecto do material aplicado, a célula à base de Sulfeto de Cádmio (CdS) é a que mais se identifica com as características de resposta espectral pretendida nesta aplicação, que é a detecção de variações eletromagnéticas situadas no campo do espectro visível.

A Clairex Technologies, Inc. (http://www.clairex.com), oferece uma variedade de cinco materiais à base de $\mathrm{CdS}$ utilizados para a fabricação de células fotorresistivas. O Quadro 1 relaciona estes materiais e apresenta uma breve descrição das principais características e indicações para aplicação.

A partir do Quadro 1, é possível selecionar o material adequado para a aplicação através dos seguintes passos: 


\begin{tabular}{|c|c|}
\hline uadro & Materia \\
\hline & Sulfeto \\
\hline Tipo & Características básicas \\
\hline 2 & $\begin{array}{l}\text { Resposta espectral de pico em } 515 \mathrm{~nm} \text {, mate- } \\
\text { rial fotossensível de resposta centrada na cor } \\
\text { azul, alta estabilidade, baixo erro por tempera- } \\
\text { tura. Pode ser usado em aplicações onde se exija } \\
\text { nítida diferenciação das cores situadas entre o } \\
\text { azul e o verde. Para uso com lâmpadas fluores- } \\
\text { centes ou incandescentes. }\end{array}$ \\
\hline 5 & 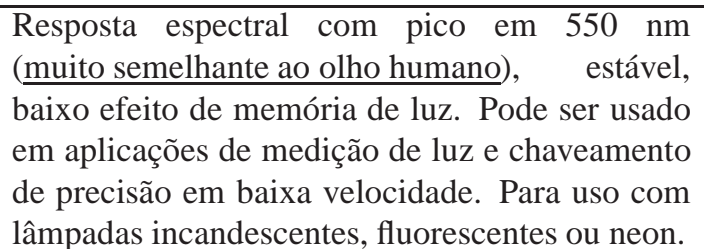 \\
\hline $5 \mathrm{H}$ & $\begin{array}{l}\text { Resposta espectral com pico em } 550 \mathrm{~nm} \\
\text { (muito semelhante ao olho humano). Combina } \\
\text { alta velocidade, estabilidade, linearidade e res- } \\
\text { posta de temperatura de cor uniforme. Pode ser } \\
\text { usado em chaveamento de alta velocidade ou me- } \\
\text { dições de alta estabilidade. Para uso com lâmpa- } \\
\text { das incandescentes, fluorescentes ou neon. }\end{array}$ \\
\hline 7 & $\begin{array}{l}\text { Resposta espectral com pico em } 615 \mathrm{~nm} \text {, velo- } \\
\text { cidade e relação moderadas. Pode ser usada em } \\
\text { aplicações de detecção de objetos por interrupção } \\
\text { de feixe de luz. Para uso com lâmpadas incandes- } \\
\text { centes, fluorescentes ou neon. }\end{array}$ \\
\hline $7 \mathrm{H}$ & $\begin{array}{l}\text { Resposta espectral com pico em } 620 \mathrm{~nm} \text {, curto } \\
\text { tempo de descida (decay time) combinado com } \\
\text { baixa resistência e alta inclinação (slope). Ideal } \\
\text { para chaveamentos rápidos entre níveis de luz } \\
\text { próximos ou quando a estabilidade de tempera- } \\
\text { tura é crítica. }\end{array}$ \\
\hline
\end{tabular}

- A primeira e fundamental característica, é que o sensor deva apresentar uma resposta espectral, cuja abrangência cubra a faixa sensível ao olho humano. Os itens que atendem este quesito são os tipos $\mathbf{5}$ e $\mathbf{5 H}$.

- De acordo com as informações apresentadas pelas folhas de dados da Clairex, a diferenciação básica existente entre os materiais dos tipos 5 e $5 \mathrm{H}$ está na velocidade de resposta. Ainda de acordo com o manual, a definição de velocidade de resposta de uma célula fotocondutiva é analisada a partir dos seguintes termos e condições:

Tempo de Subida $\left(\boldsymbol{T}_{s}\right)$ (rise time) de uma célula fotocondutiva é o tempo necessário para que, uma vez adaptada por 5 segundos no escuro total, a corrente suba (diminuição de resistência) a 63,2\% de seu valor máximo após ter sido iluminada; e

Tempo de Descida $\left(\boldsymbol{T}_{d}\right)$ (decay time) é o tempo neces-
Tabela 1: Tempo de Resposta versus Luz dos materiais Clairex tipos 5 e $5 \mathrm{H}$.

\begin{tabular}{|c|c|c|c|c|c|c|}
\hline $\begin{array}{c}\text { Iluminação } \\
\text { Em foot } \\
\text { candles }\end{array}$ & & .01 & 0.1 & 1.0 & 10 & 100 \\
\hline \multirow{2}{*}{$\begin{array}{l}T_{s} \text { (rise time) } \\
\text { em segundos }\end{array}$} & $\begin{array}{c}\text { tipo } \\
5\end{array}$ & 5.80 & .82 & .140 & .035 & .010 \\
\hline & $\begin{array}{c}\text { tipo } \\
5 \mathrm{H}\end{array}$ & 1.46 & .116 & .030 & .005 & .002 \\
\hline \multirow{2}{*}{$\begin{array}{c}T_{d}(\text { decay time }) \\
\text { em segundos }\end{array}$} & $\begin{array}{c}\text { tipo } \\
5\end{array}$ & 2.96 & .56 & .110 & .043 & .014 \\
\hline & $\begin{array}{c}\text { tipo } \\
5 \mathrm{H}\end{array}$ & .159 & .019 & .004 & .002 & .001 \\
\hline
\end{tabular}

sário para que a corrente decresça (aumento de resistência) após remoção da luz.

Para auxiliar na seleção final, a Tabela 1 apresenta os dados comparativos das velocidades de resposta em função do nível de iluminação dos tipos de células 5 e $5 \mathrm{H}$.

Pode-se verificar, pelos dados da Tabela 1, que para todas as faixas de iluminação apresentadas, o material do tipo $5 \mathrm{H}$ apresenta valores de 4 a 7 vezes menor de tempo de subida $\left(T_{s}\right)$ e de 14 a 29 vezes menor de tempo de descida $\left(T_{d}\right)$, quando comparados às velocidades de resposta do material de tipo 5 .

Assim sendo, por apresentar uma característica de velocidade bem mais rápida, o material fotossensível Clairex selecionado é o de tipo $\mathbf{5 H}$.

Uma vez que o material fotocondutivo esteja selecionado, é necessário escolher o invólucro físico apropriado. A Clairex apresenta duas opções de invólucros para as células fotorresistivas: encapsulamento em epoxy (série CL7P) e hermeticamente selada (série CL700). Além da proteção adicional, as células hermeticamente encapsuladas permitem uma dissipação de potência duas vezes maior que as equivalentes em epoxy, motivo pelo qual esta linha será a escolhida.

Desta forma, a célula fotorresistiva selecionada para esta aplicação resulta na Clairex modelo CL705HL.

\section{DETECTOR FOTOELÉTRICO}

Após feita a seleção do elemento fotossensível, um passo importante para a concepção do transdutor fotoelétrico é a configuração do sistema óptico, que irá efetuar a projeção de luz e a captação dos raios refletidos pela superfície sensoriada. 
Para se alcançar o maior ganho óptico em sensibilidade, os seguintes aspectos devem ser considerados:

- a interferência entre os dois canais de luz (projeção e reflexão) deve ser nula; e

- a luz que se propaga da fonte primária até a região sensível da célula deve encontrar a menor resistência e a melhor distribuição possíveis.

\subsection{Construção do Detector Fotoelétrico}

Procurou-se, nesta fase, a experimentação de técnicas e materiais alternativos para a condução, concentração e dispersão de luz. Isto culminou na idealização de um prático e simples feixe de fibras ópticas em detrimento da utilização dos tradicionais, caros, frágeis (e de difícil aquisição) elementos geométricos da óptica, tais como as lentes, prismas, espelhos etc. O tipo de fibra escolhida foi a plástica do tipo multimodo degrau, com diâmetro de núcleo de $1 \mathrm{~mm}$ e sem capa protetora externa (Hechy, 1993).

A este conjunto, cujo desenho está apresentado na Figura 10, é atribuído o nome detector fotoelétrico. De todas as configurações experimentadas para a montagem do feixe, o arranjo que melhor conciliou as dimensões da linha a ser detectada com as características físicas dos componentes ópticos selecionados foi a construção de dois canais de luz confeccionados pelo arranjo de quatro fibras dispostas linearmente, de modo que sua secção apresentasse aproximadamente a geometria de um retângulo com dimensões de 4 x $1 \mathrm{~mm}$. Um desses feixes compõe o canal de projeção de luz e, o segundo, o canal da luz refletida.

Como fonte de luz de cor branca, foi selecionada uma lâmpada incandescente miniatura, tipo $K 14 X$ da Koomei (http://www.koomei.com.br). Todos os componentes ópticos foram acomodados em um corpo de alumínio monobloco, compacto e extremamente robusto.

\subsection{Testes do Detector Fotoelétrico}

A Tabela 2 apresenta os valores de resistência obtidos experimentalmente, submetendo-se a linha impressa a desvios de deslocamentos graduados em $0,05 \mathrm{~mm}$, num intervalo compreendido entre $-0,7 \mathrm{~mm}$ e $+0,7 \mathrm{~mm}$, empregando-se o dispositivo da Figura 8. Durante os testes, foi também analisado o comportamento da resposta do detector em função da proximidade ao plano de leitura. Os melhores desempenhos foram observados quando a face inferior do detector se distanciava entre 1,5 e $2 \mathrm{~mm}$ do plano leitor.

Dados operacionais:

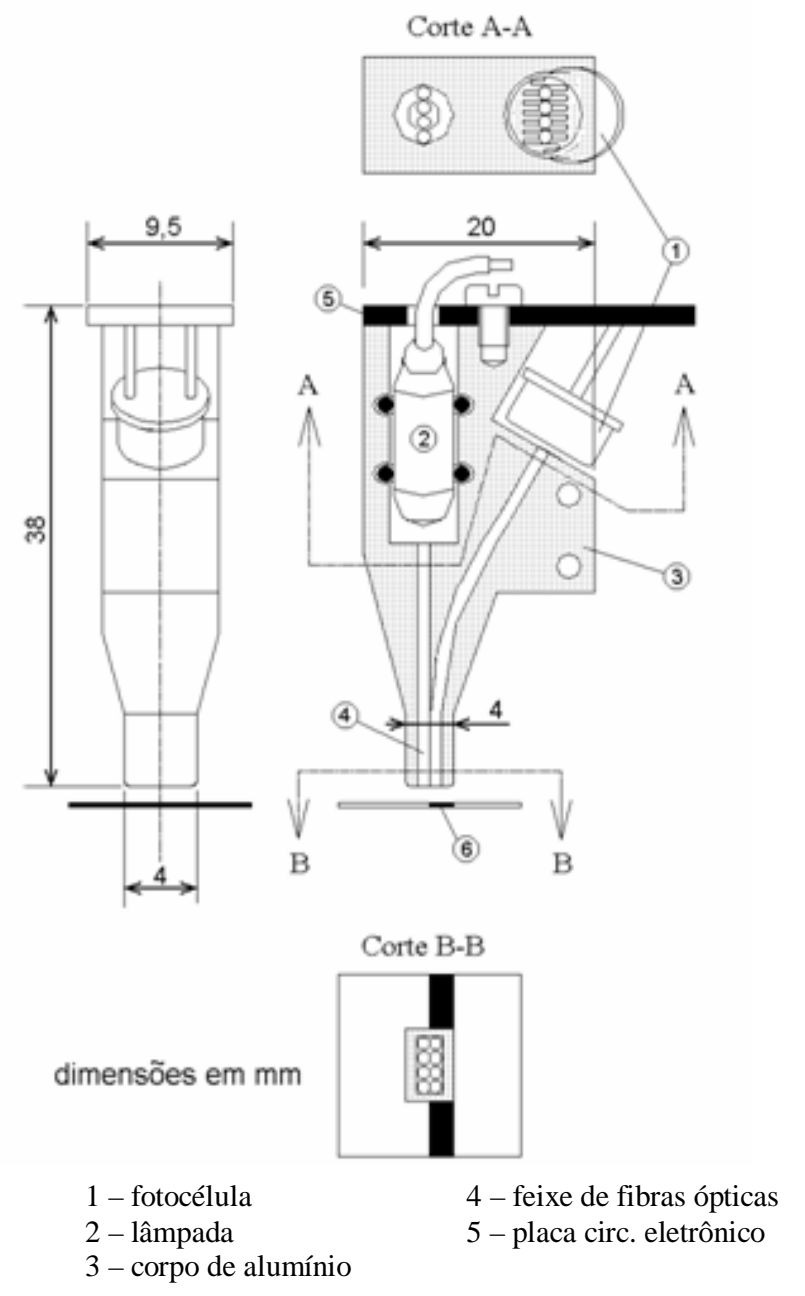

Figura 10: Desenho construtivo do detector fotoelétrico.

- detector fotoelétrico montado com a fotocélula tipo CL705HL da Clairex,

- fonte de luz: lâmpada Koomei modelo $K 14 X$,

- tensão nominal: $6.0 \mathrm{~V}$ - $200 \mathrm{~mA}$; tensão de trabalho: $5.0 \mathrm{~V}-190 \mathrm{~mA}$.

O gráfico da função de resposta estática obtido através dos dados levantados é apresentado na Figura 11.

Analisando-se a curva da Figura 11, nota-se que a taxa de variação da resistência para os desvios positivos (de 0 a +0,7 $\mathrm{mm}$ ) é maior que os apresentados para os desvios negativos (de 0 a $-0,7 \mathrm{~mm}$ ). Este fato se deve à característica de resposta da fotocélula que se assemelha a uma função logarítmica. Explorando esta característica, resolveu-se experimentar a aplicação de um resistor conectado em paralelo à fotocélula a fim de, em detrimento da queda de ganho, melhorar a linearidade da resposta final. 
Tabela 2: Dados experimentais obtidos do detector fotoelétrico. $\mathbf{D}=$ Deslocamento [mm], $\mathbf{R}=$ Resistência [kOhms]

\begin{tabular}{|c|c|c|c|c|}
\hline $\boldsymbol{D}$ & $\boldsymbol{R}$ & & $\boldsymbol{D}$ & $\boldsymbol{R}$ \\
\hline$-0,70$ & 2,4 & & $+0,05$ & 8,5 \\
\hline$-0,65$ & 2,5 & & $+0,10$ & 9,4 \\
\hline$-0,60$ & 2,6 & & $+0,15$ & 10,4 \\
\hline$-0,55$ & 2,7 & & $+0,20$ & 11,8 \\
\hline$-0,50$ & 2,9 & & $+0,25$ & 12,4 \\
\hline$-0,45$ & 8,1 & & $+0,30$ & 18,8 \\
\hline$-0,40$ & 8,8 & & $+0,35$ & 14,4 \\
\hline$-0,35$ & 8,5 & & $+0,40$ & 15,5 \\
\hline$-0,30$ & 8,9 & & $+0,45$ & 16,2 \\
\hline$-0,25$ & 4,8 & & $+0,50$ & 16,8 \\
\hline$-0,20$ & 4,8 & & $+0,55$ & 17,6 \\
\hline$-0,15$ & 5,4 & & $+0,60$ & 17,9 \\
\hline$-0,10$ & 5,9 & & $+0,65$ & 18,8 \\
\hline$-0,05$ & 6,7 & & $+0,70$ & 18,6 \\
\hline$-0,00$ & 7,5 & & & \\
\hline
\end{tabular}

Tal procedimento se fundamenta no fato que, quando associados em paralelo, a interferência da resistência de valor fixo tem maior grau de influência no resultado da associação quando a fotocélula estiver variando na região correspondente aos valores mais altos. A fórmula a seguir auto-explica o fato:

$$
R_{\text {equivalente }}=\frac{R_{\text {fixa }} \cdot R_{\text {variavel }}}{R_{\text {fixa }}+R_{\text {variavel }}}
$$

Procurou-se determinar um valor adequado de $R_{\text {fixa }}$, de modo que fosse garantida, em qualquer ponto de excursão da curva, a obtenção de taxas de variação razoáveis de resistência (algo em torno de $100 \mathrm{Ohms} / 0,1 \mathrm{~mm}$ ) da $R_{\text {equivalente }}$. A alternativa considerada ótima foi alcançada com $R_{\text {fixa }}=$ $10 \mathrm{kOhms}$, atendendo plenamente às especificações impostas. Mesmo nos pontos mais críticos da curva (extremos inferior e superior), as taxas de variação apresentadas foram de, respectivamente, 180 e $90 \mathrm{Ohms} / 0,1 \mathrm{~mm}$.

Os valores obtidos com esta implementação são apresentados na Tabela 3 e o gráfico da função de resposta é apresentado na Figura 12.

\section{Dados operacionais:}

- detector fotoelétrico montado com a fotocélula tipo

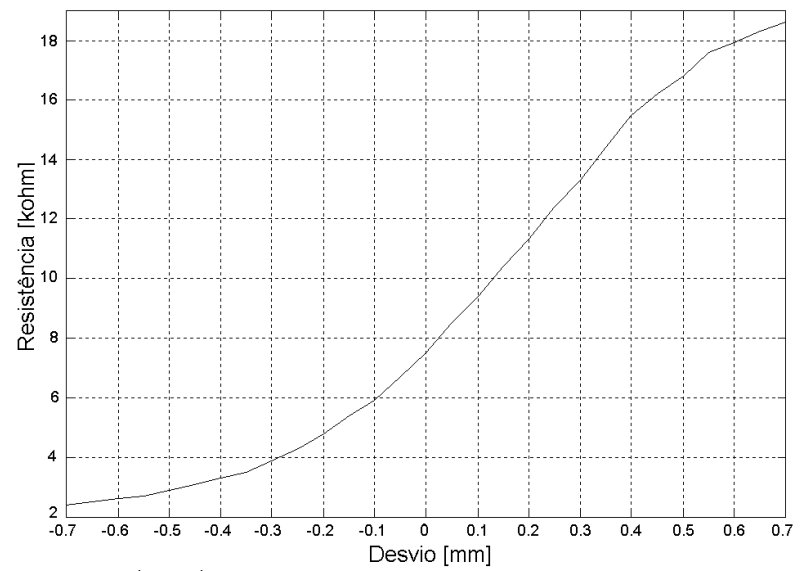

Figura 11: Gráfico da função de resposta do detector fotoelétrico.



Figura 12: Gráfico da função de resposta estática do detector fotoelétrico.

CL705HL da Clairex, acoplado com uma resistência de $10 \mathrm{kOhm}$ em paralelo,

- fonte de luz e tensão nominal: mesmas da tabela 2.

As amplitudes das duas curvas obtidas podem ser comparadas observando-se a Figura 13, que apresenta um gráfico com eixos de coordenadas comuns.

Nota-se que houve sensível redução no valor final da resistência medida, entretanto, com taxas muito mais acentuadas para os desvios positivos (entre $0 \mathrm{e}+0,7 \mathrm{~mm}$ ). A comparação das curvas, onde se destaca o ganho em linearidade obtido com a versão implementada com a resistência de 10 kOhms em paralelo, é feita através dos gráficos superpostos apresentados na Figura 14.

Pode-se finalmente concluir, analisando-se a superposição de 
Tabela 3: Dados calculados de $R_{\text {equivalente }}$ do detector fotoelétrico. $\mathbf{D}=$ Deslocamento [mm], $\mathbf{R}=$ Resistência $[\mathrm{kOhms}]$

\begin{tabular}{|c|c|c|c|c|}
\hline $\boldsymbol{D}$ & $\boldsymbol{R}$ & & $\boldsymbol{D}$ & $\boldsymbol{R}$ \\
\hline$-0,70$ & 1,985 & & $+0,05$ & 4,594 \\
\hline$-0,65$ & 2,000 & & $+0,10$ & 4,845 \\
\hline$-0,60$ & 2,068 & & $+0,15$ & 5,098 \\
\hline$-0,55$ & 2,126 & & $+0,20$ & 5,805 \\
\hline$-0,50$ & 2,248 & & $+0,25$ & 5,585 \\
\hline$-0,45$ & 2,866 & & $+0,30$ & 5,708 \\
\hline$-0,40$ & 2,481 & & $+0,35$ & 5,901 \\
\hline$-0,35$ & 2,592 & & $+0,40$ & 6,078 \\
\hline$-0,30$ & 2,805 & & $+0,45$ & 6,188 \\
\hline$-0,25$ & 8,007 & & $+0,50$ & 6,268 \\
\hline$-0,20$ & 8,248 & & $+0,55$ & 6,876 \\
\hline$-0,15$ & 8,506 & & $+0,60$ & 6,415 \\
\hline$-0,10$ & 8,710 & & $+0,65$ & 6,466 \\
\hline$-0,05$ & 4,012 & & $+0,70$ & 6,508 \\
\hline$-0,00$ & 4,285 & & & \\
\hline
\end{tabular}

curvas apresentada na Figura 14, que o resultado alcançado com a implementação do resistor paralelo à fotocélula gerou, em conseqüência, uma curva de resposta estática (-o-o-) com características de linearidade satisfatórias. Quando comparada à curva de resposta ideal (- - -), constata-se a estreita proximidade e excelente simetria, equilíbrio não alcançado anteriormente pela curva de resposta ( - ) obtida com a fotocélula aplicada isoladamente ao conjunto óptico.

Pelos motivos acima expostos, será esta a versão a ser implementada no detector fotoelétrico.

\subsection{Circuito Eletrônico para o Transdutor Fotoelétrico}

A função do circuito eletrônico é de, quando acoplado ao detector fotoelétrico, converter as informações de deslocamento da linha impressa em um sinal de saída padronizado e com características tais que a transmissão do mesmo possa ocorrer, preservando-se as informações nele contidas.

Ao conjunto final detector fotoelétrico/circuito eletrônico/ gabinete de montagem atribui-se o nome transdutor fotoelétrico. O esquema final do circuito eletrônico implementado com todos os recursos exigidos para composição do transdutor fotoelétrico é apresentado na Figura 15.

Os amplificadores em ponte são provavelmente os de uso

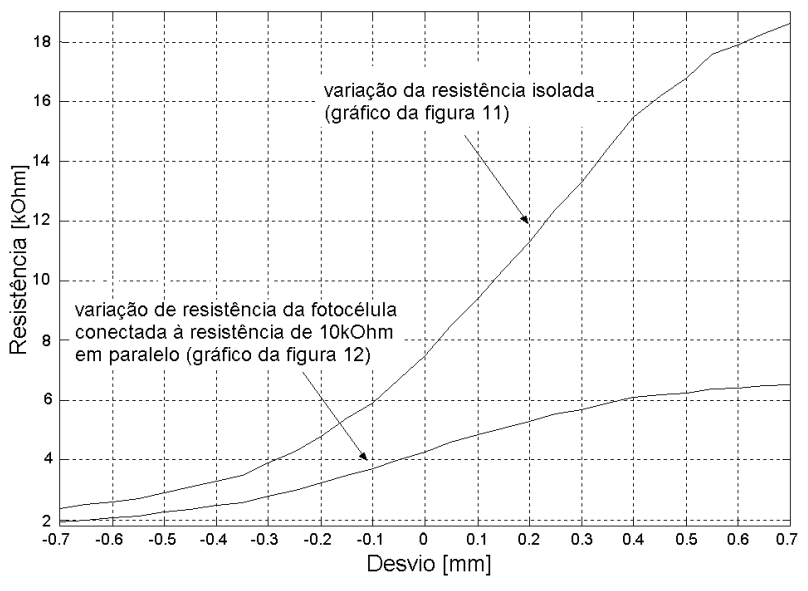

Figura 13: Comparação das amplitudes das curvas de respostas estáticas obtidas.

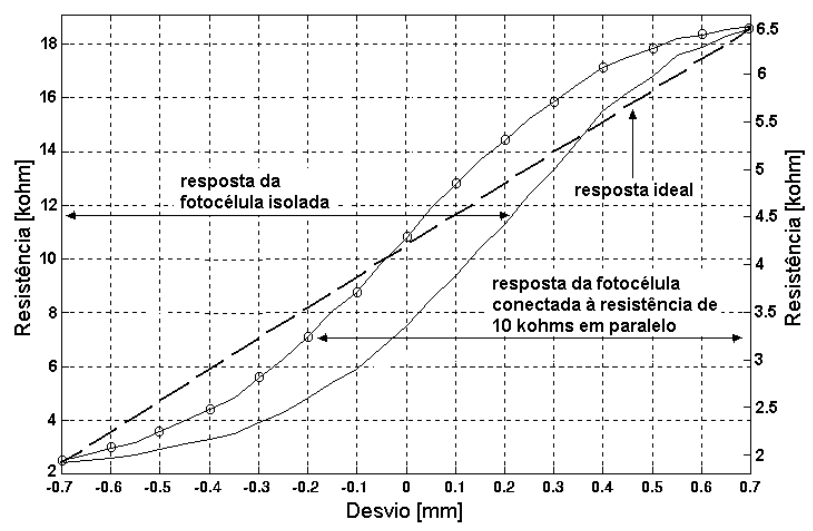

Figura 14: Comparação da linearidade das curvas de respostas estáticas obtidas.

mais comum em instrumentação (Graeme, 1973). Dentre os diversos circuitos experimentados, a configuração selecionada foi a de um amplificador de corrente de meia-ponte.

\section{TRANSDUTOR FOTOELÉTRICO}

Os elementos componentes do transdutor fotoelétrico foram acomodados de forma compacta e protegida em uma caixa de alumínio no formato de 90 × 50 × $25 \mathrm{~mm}$. O dispositivo é apresentada na Figura 16, onde estão identificados os comandos operacionais e indicador (tipo bargraph) de nível do sinal de saída $(0 \pm 10 \mathrm{~V})$.

\subsection{Comportamento Estático do Transdu- tor Fotoelétrico}

Para análise do comportamento estático do transdutor fotoelétrico, elaborou-se um ensaio, a fim de se obter sua fun- 


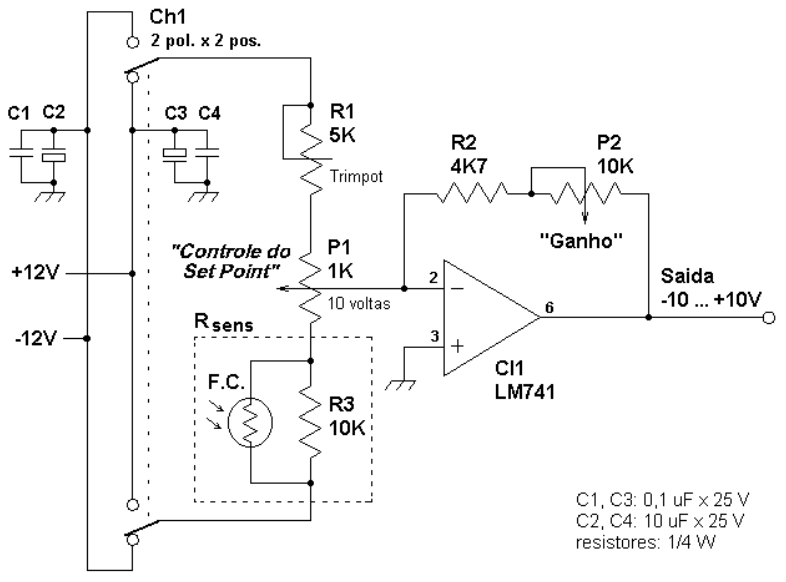

Figura 15: Configuração final do circuito eletrônico para o transdutor fotoelétrico.

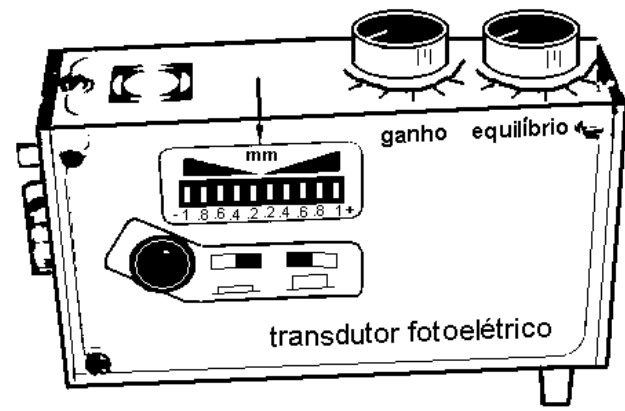

Figura 16: Esboço do protótipo do transdutor fotoelétrico.

ção de resposta estática. Sabe-se que a faixa de entrada do transdutor fotoelétrico é representada pelo deslocamento da linha impressa (entre $-0,7$ e $+0,7 \mathrm{~mm}$ ). Correspondente a esta faixa de deslocamento de entrada, ocorre, na saída, uma conseqüente variação em tensão situada na faixa entre -10 e +10V. Os dados resultantes estão apresentados na Tabela 4.

\section{Dados operacionais:}

- controle do set point (P1) na posição central,

- tensão de saída medida com o terminal comum (terra) do voltímetro conectado em $0 \mathrm{~V}$.

O gráfico da resposta estática é mostrado na Figura 17.

\subsection{Modelagem Dinâmica do Transdutor Fotoelétrico}

Os elementos sensores fotorresistivos apresentam características de resposta similares aos extensômetros (strain gauges)
Tabela 4: Dados experimentais obtidos do transdutor fotoelétrico. $\mathbf{D}=$ Deslocamento $[\mathrm{mm}], \mathbf{R}=$ Resistência [kOhms]

\begin{tabular}{|c|c|c|c|c|}
\hline $\boldsymbol{D}$ & $\boldsymbol{R}$ & & $\boldsymbol{D}$ & $\boldsymbol{R}$ \\
\hline$-0,70$ & - & & $+0,05$ & 1,64 \\
\hline$-0,65$ & $-9,71$ & & $+0,10$ & 2,74 \\
\hline$-0,60$ & $-9,44$ & & $+0,15$ & 3,85 \\
\hline$-0,55$ & $-9,16$ & & $+0,20$ & 4,76 \\
\hline$-0,50$ & $-8,63$ & & $+0,25$ & 5,76 \\
\hline$-0,45$ & $-8,11$ & & $+0,30$ & 6,52 \\
\hline$-0,40$ & $-7,61$ & & $+0,35$ & 7,36 \\
\hline$-0,35$ & $-7,12$ & & $+0,40$ & 8,14 \\
\hline$-0,30$ & $-6,19$ & & $+0,45$ & 8,60 \\
\hline$-0,25$ & $-5,31$ & & $+0,50$ & 8,97 \\
\hline$-0,20$ & $-4,27$ & & $+0,55$ & 9,44 \\
\hline$-0,15$ & $-3,12$ & & $+0,60$ & 9,61 \\
\hline$-0,10$ & $-2,23$ & & $+0,65$ & 9,84 \\
\hline$-0,05$ & $-0,91$ & & $+0,70$ & 10,00 \\
\hline$-0,00$ & 0,29 & & & \\
\hline
\end{tabular}

e aos sensores de temperatura do tipo termo-resistivos. Estes elementos comumente são modelados como um sistema de $1^{a}$ ordem, que incorporam um atraso de transferência devido ao efeito combinado de suas propriedades resistivas e capacitivas (Garcia, 2005).

A Figura 18 apresenta o diagrama de blocos simplificado deste sistema, cuja relação entrada-saída seja dada por:

$$
G_{M}(s)=\frac{B(s)}{C(s)}=\frac{K_{M}}{1+\tau_{M} \cdot s}
$$

A monitoração do sinal de saída do transdutor foi realizada com o auxílio de um osciloscópio conectado ao terminal de saída do transmissor eletrônico. O terminal comum (terra) da ponta de prova do osciloscópio foi conectado ao ponto de $-10 \mathrm{~V}$ para que o sinal na tela representasse a variação $\mathrm{em}$ módulo do sinal, isto é, excursão total máxima compreendida entre 0 e $+20 \mathrm{~V}$. Após ajustar e estabilizar o disco mostrado na Figura 9 a uma rotação adequada, obteve-se na tela do osciloscópio o sinal apresentado na Figura 19.

Efetuando-se a leitura do valor da constante de tempo a partir da curva experimental e substituindo-se na equação (2), resulta a seguinte função de transferência entre a tensão de saída e o desvio de contraste: 


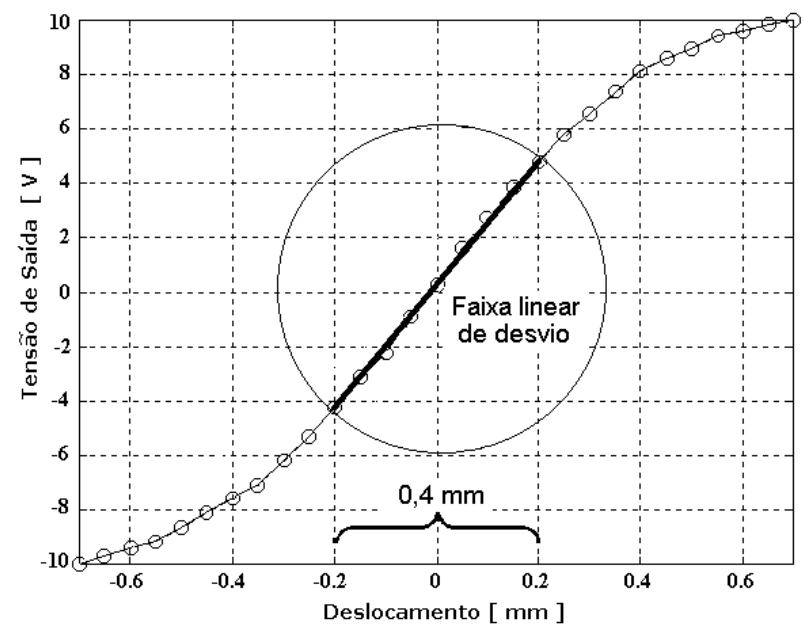

Figura 17: Gráfico da curva de resposta estática experimental do transdutor a uma solicitação em rampa de $-0,7$ a $0,7 \mathrm{~mm}$.

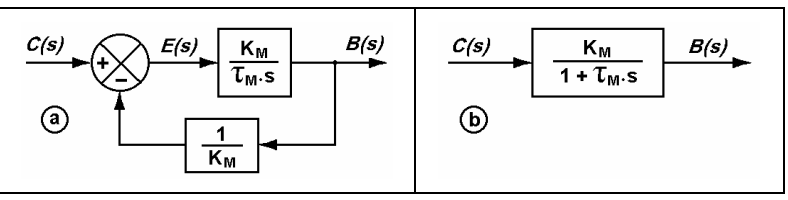

Figura 18: (a) Diagrama de blocos de um sistema de primeira-ordem; (b) Diagrama de blocos simplificado.

$$
G_{M}(s)=\frac{B(s)}{C(s)}=\frac{K_{M}}{1+0,004 \cdot s}
$$

É notório que, para o desvio de $\pm 0,2 \mathrm{~mm}$ no entorno do ponto de operação, a curva apresentada na Figura 17 pode ser considerada linear. Esta faixa de desvio é a mínima que atende à precisão de corte de $0,4 \mathrm{~mm}$, apresentada na seção 2.2 .

Para este caso, a função de transferência representada pela equação (3) pode ter o fator de ganho $K_{M}$ calculado na forma:

$$
K_{M}=\frac{\Delta V}{\Delta D}=\frac{[4,76-(-4,27)]}{[0,2-(-0,2)]}=22,575
$$

que substituído em (3) resulta:

$$
G_{M}(s)=\frac{B(s)}{C(s)}=\frac{22,575}{1+0,004 \cdot s}
$$

A trajetória a ser percorrida pelo suporte (trajetória de acomodação) entre os pontos (8)-carro desbobinador e (7)-facas

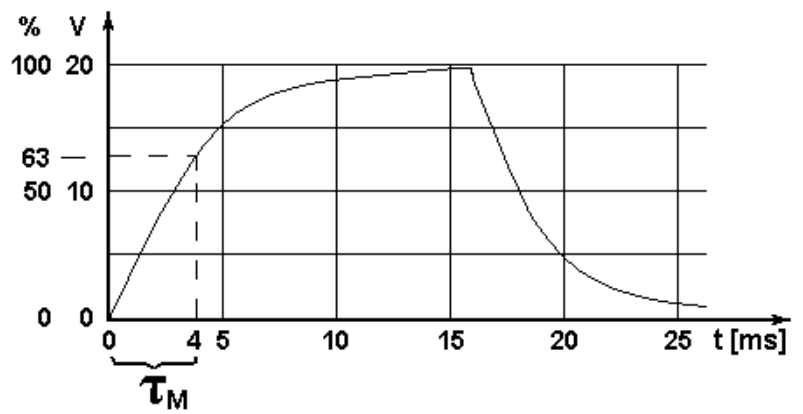

Figura 19: Tela do osciloscópio apresentando a resposta dinâmica do transdutor fotoelétrico a uma entrada em degrau.

da Figura 1 deve ter uma distância longa o suficiente, para evitar que os deslocamentos transversais provoquem deformações ou ruptura do material durante o processo. As variáveis que concorrem para este dimensionamento são a tensão de trabalho, o módulo de elasticidade do material-suporte e o nível de correção exigido. Experiências têm mostrado que esta distância deve estar na faixa entre 2 a 3 vezes a largura do suporte (Erhardt-Leimer, 2005). É também durante esta trajetória que o suporte deve ser recomposto em seu alinhamento antes de alcançar as facas, garantindo assim um perfeito sincronismo na operação de corte.

Considere que uma bobina de $1 \mathrm{~m}$ de largura seja submetida ao controle de alinhamento em uma máquina cortadeirarebobinadeira cuja trajetória de acomodação seja a mínima, ou seja, $2 \mathrm{~m}$ e que a velocidade de trabalho seja de 800 $\mathrm{m} / \mathrm{min}$. Apesar de improvável, considere-se ainda que a bobina sofra um desvio em degrau de $1 \mathrm{~mm}$ - pior situação - e que o atuador que interage junto ao carro que suporta a bobina tenha uma velocidade máxima de correção de $25 \mathrm{~mm} / \mathrm{s}$. Supondo-se que o controlador desse sistema seja de ação proporcional com ganho unitário e com uma resolução de erro de 0,1 mm, o tempo de atuação necessário para recompor o alinhamento do suporte pode ser resumido conforme a progressão e totalização apresentada na Tabela 5.

Dados operacionais:

- controlador proporcional,

- velocidade máxima de correção de $25 \mathrm{~mm} / \mathrm{s}$,

- desvio em degrau de $1 \mathrm{~mm}$.

Para uma velocidade de trabalho de $800 \mathrm{~m} / \mathrm{min}$, o suporte ao fim deste tempo terá percorrido:

Avanço do suporte $=\frac{800 \times 0,1172}{60}=1,563 \mathrm{~m}$ 
Tabela 5: Tempo do atuador para correção.

\begin{tabular}{|c|c|c|}
\hline $\begin{array}{l}\text { Erro } \\
{[\mathrm{mm}]}\end{array}$ & $\begin{array}{c}\text { Velocidade } \\
\text { Instantânea } \\
{[\mathrm{mm} / \mathrm{s}]}\end{array}$ & $\begin{array}{c}\text { Tempo de reposição } \\
\text { para } 0,1 \mathrm{~mm} \text { [ms] }\end{array}$ \\
\hline 1 & 25,0 & 4,0 \\
\hline 0,9 & 22,5 & 4,4 \\
\hline 0,8 & 20,0 & 5,0 \\
\hline 0,7 & 17,5 & 5,7 \\
\hline 0,6 & 15,0 & 6,7 \\
\hline 0,5 & 12,5 & 8,0 \\
\hline 0,4 & 10,0 & 10,0 \\
\hline 0,3 & 7,5 & 13,3 \\
\hline 0,2 & 5,0 & 20,0 \\
\hline 0,1 & 2,5 & 40,0 \\
\hline \multicolumn{2}{|c|}{ Tempo total de atuação [ms] } & 117,2 \\
\hline
\end{tabular}

ou seja, apenas $78 \%$ dos $2 \mathrm{~m}$ de percurso disponível pelo trajeto de acomodação.

Levando-se em consideração a constante de tempo do sensor de $4 \mathrm{~ms}$ (Figura 19), tem-se que o tempo de acomodação $t_{s}$ para que a curva de resposta alcance e permaneça dentro de uma faixa em torno de $2 \%$ do valor final é de:

$$
t_{s}=4 \times 4=16 \mathrm{~ms}
$$

Comparando-se, para o sinal de desvio em degrau aplicado, o tempo de resposta do atuador (117,2 ms) com o tempo de acomodação do sinal do sensor (16 ms), constata-se que o desempenho do sensor apresenta enorme margem de folga perante este parâmetro do sistema.

\section{CONCLUSÕES}

A proposta de se montar um transdutor fotoelétrico, partindo da seleção de qual seria o melhor sensor óptico foi realizada. Foram apresentados diversos tipos de sensores ópticos e o melhor, para a aplicação proposta, foi escolhido. Procedeuse então à montagem do transdutor fotoelétrico, com auxílio de um circuito eletrônico que convertia o sinal de saída do sensor óptico (Ohms) em Volts.

O transdutor fotoelétrico foi submetido a ensaios estáticos e dinâmicos, utilizando-se os dispositivos medidor de desvios (Figura 8) e gerador de impulsos (Figura 9), tendo-se mostrado apto a operar em máquinas cortadeiras-rebobinadeiras de alta velocidade (até $800 \mathrm{~m} / \mathrm{min}$ ).

\section{REFERÊNCIAS}

Erhardt-Leimer. Dispositivos de rolos-guia. Elroller guides. Steering roller assemblies. Disponível em: <http://www.erhardt-leimer-us.com/roller.htm>. Acesso em 11/abr de 2005.

Garcia, Claudio. Modelagem e simulação de processos industriais e de sistemas eletromecânicos. $2^{a}$ edição, São Paulo. Editora da Universidade de São Paulo. 2005. $670 \mathrm{p}$.

Graeme, Jerald G. Applications of operational amplifiers: third-generation techniques. USA. Burr-Brown Research Corporation. 1973. 233p.

Günter, Wyszecki; Stiles, Walter S. Color science. USA, New York. John Wiley \& Sons, Inc. 1967. 628p.

Hecht, Eugene; Zajac, Alfred. Optics. Philippines. AddisonWesley Publishing Company. 1974. 565p.

Hechy, Jeff. Entendendo fibras óticas. Tradução de Roberto R. Tavares. Rio de Janeiro, RJ: Berkeley, 1993. 554p.

Soroda, Walter. Fundamentals of packaging technology. M. Mowbray: The Institute of Packaging, 1996. 464p. 